\title{
$-0$ \\ On the Nature, Modeling, and Neural Bases of Social Ties
}

Frans van Winden'

Mirre Stallen ${ }^{2}$

Richard Ridderinkhof

' CREED, University of Amsterdam, CEPR, CESifo, and Tinbergen Institute;

2 Erasmus Research Institute of Management (ERIM), Erasmus University Rotterdam, and Radboud University, Nijmegen;

${ }^{3}$ Amsterdam Center for the Study of Adaptive Control in Brain and Behavior (ACACIA), Dept. of Psychology, University of Amsterdam. 


\section{Tinbergen Institute}

The Tinbergen Institute is the institute for economic research of the Erasmus Universiteit Rotterdam, Universiteit van Amsterdam, and Vrije Universiteit Amsterdam.

Tinbergen Institute Amsterdam

Roetersstraat 31

1018 WB Amsterdam

The Netherlands

Tel.: +31(0)205513500

Fax: $+31(0) 205513555$

Tinbergen Institute Rotterdam

Burg. Oudlaan 50

3062 PA Rotterdam

The Netherlands

Tel.: + $31(0) 104088900$

Fax: $+31(0) 104089031$

Most TI discussion papers can be downloaded at http://www.tinbergen.nl. 


\title{
On the Nature, Modeling, and Neural Bases of Social Ties
}

\author{
FranS VAN WINDEN ${ }^{1}$, MiRRE STALLEN ${ }^{2}$, AND K. RICHARD RIDDERINKHOF ${ }^{3}$ \\ ${ }^{1 \#}$ CREED-University OF AMSTERDAM, CEPR, CESIFO, AND TINBERGEN INSTITUTE \\ ${ }^{2}$ ERASMUS RESEARCH INSTITUTE OF MANAGEMENT (ERIM), ERASMUS UNIVERSITY, \\ ROTTERDAM AND RADBOUD UNIVERSITY, NIJMEGEN \\ ${ }^{3}$ AMSTERDAM CENTER FOR THE STUDY OF ADAPTIVE CONTROL IN BRAIN AND BEHAVIOR \\ (ACACIA), DEPARTMENT OF PSYCHOLOGY, UNIVERSITY OF AMSTERDAM
}

Forthcoming in: Daniel E. Houser and Kevin A. McCabe (Eds.), Neuroeconomics, Vol. 19, Advances in Health Economics and Health Services Research, Emerald Insight Publishing.

June 2008

\footnotetext{
\# Corresponding author: Frans van Winden, CREED/Department of Economics, University of Amsterdam, Roetersstraat 11, 1018 WB Amsterdam, Netherlands. E-mail: f.a.a.m.vanwinden@uva.nl
} 


\section{Structured Abstract}

\section{Purpose}

This paper addresses the nature, formalization, and neural bases of (affective) social ties and discusses the relevance of ties for health economics. A social tie is defined as an affective weight attached by an individual to the well-being of another individual ('utility interdependence'). Ties can be positive or negative, and symmetric or asymmetric between individuals. Characteristic of a social tie, as conceived of here, is that it develops over time under the influence of interaction, in contrast with a trait like altruism. Moreover, a tie is not related to strategic behavior such as reputation formation but seen as generated by affective responses.

\section{Methodology/approach}

A formalization is presented together with some supportive evidence from behavioral experiments. This is followed by a discussion of related psychological constructs and the presentation of suggestive existing neural findings. To help prepare the grounds for a modelbased neural analysis some speculations on the neural networks involved are provided, together with suggestions for future research.

\section{Findings}

Social ties are not only found to be important from an economic viewpoint, it is also shown that they can be modeled and related to neural substrates.

\section{Originality/value of the paper}

By providing an overview of the economic research on social ties and connecting it with the broader behavioral and neuroeconomics literature, the paper may contribute to the development of a neuroeconomics of social ties.

Keywords: social ties, affect, modeling, neuroeconomics

Conceptual paper 


\section{Introduction}

Interpersonal attachments appear to play a key role in human life. As extensively documented by Baumeister and Leary (1995), people form social attachments readily and resist the dissolution of existing bonds. A broad assortment of psychological evidence pleads in favor of the hypothesis put forward by these authors that the desire for affective interpersonal relationships is a fundamental human motivation. From an evolutionary viewpoint this readiness to form groups makes sense, for example, as a behavioral mechanism to protect against external threats. Furthermore, in line with the hypothesis, there are many studies indicating that mental and physical health problems are more common among people who lack close personal relationships, that is, if they involve positive interaction (op. cit., pp. 508-511; see also Berscheid and Reis, (1998)). For instance, without bonds marked by positive concern and caring, people are more likely to be unhappy, depressed, and anxious. Apart from being important for health and subjective well-being, interpersonal attachments - or, social ties, as we will call them below - show significant cognitive and emotional effects related to their tendency to blur the boundaries between the relationship partner and the self ("to include the other in the self").

Notwithstanding this wealth of evidence, processes of interpersonal attachment have been neglected in formal models of social interaction. This also holds for recent models in behavioral economics and game theory that allow for other-regarding preferences (like inequity aversion or reciprocity), as we will discuss in greater detail below. What is missing is the incorporation of affective processes providing the 'social glue' for attachment. Note that doing so would give relations an individualized, historical, and context dependent content. This would further help to bridge the gap between an 'undersocialized' and an 'oversocialized' account of human behavior that characterizes many models (Granovetter, 1985). The former is characteristic for neoclassical economic models assuming narrowly selfish behavior, while the latter characterizes models in economics and sociology assuming agents with fully internalized social norms (like fairness or equity). In both cases, behavior is atomized in the sense that it is not embedded in culture as an ongoing process that is continuously constructed and reconstructed during interaction.

The significance of affect in interpersonal relationships is increasingly acknowledged also in economics (see, e.g., Elster, 1998; Loewenstein, 2000). This tendency is reinforced by recent neuroscientific findings and the concomitant rise of social neuroeconomics (Fehr and Camerer, 2007; Sanfey, 2007). Already, a few models have been developed formalizing interpersonal behavior as the outcome of interacting affective and deliberative systems 
(Loewenstein and O'Donoghue, 2007; van Dijk and van Winden, 1997; van Winden, 2001). In this chapter, we will focus on the dual-system model of van Dijk and van Winden (1997), which explicitly deals with the affective processes involved in interpersonal attachment.

The organization of this chapter is as follows. After a brief summary of the state of the art in the (economic) modeling of social interaction, Section 2 presents an outline of the social ties model of van Dijk and van Winden (1997) and shortly reports on the behavioral experimental evidence regarding this model. Section 3 is concerned with an exploration of what we know at this stage about the neural substrates of ties, based on the existing literature, paying special attention to the constructs of empathy and sympathy. It also provides some speculations on the neural correlates of social ties. Section 4 concludes.

\section{Social ties}

\subsection{Social ties: Introduction}

Economists are well aware that for a variety of strategic and non-strategic reasons individuals may show behavior that seems to conflict with the assumed behavior of homo economicus the fully rational and narrowly selfish agent populating most economic models (see e.g. Fehr and Schmidt, 2005; Sobel, 2005) One strategic reason is that such behavior may help to build up a reputation (e.g., of being cooperative) which is expected to further one's selfish interests in the future, even though it hurts these interests in the short-run. While this is still compatible with narrowly selfish behavior, this is not the case with another (non-strategic) reason that regularly pops up in the literature, which is altruism, that is, behavior that is costly to the actor and beneficial to the recipient. Envy or spitefulness, defined as costly behaviors that are also costly for the recipient, have received some attention too, albeit to a much lesser extent. Both types of (unconditional) behavior are assumed to stem from other-regarding preferences, formalized through interdependent utility functions, where, in the case of altruism (envy), a positive (negative) weight is attached to the utility or welfare of other individuals.

More recently, another type of other-regarding preference, related to inequity aversion, has attracted much attention. In that case, an individual's utility function is embellished with an argument representing differences in payoffs with other individuals. A different strand of recent models focuses on intention-based reciprocity, defined as costly (un)kind behavior in response to the (un)kind behavior of another person. This is modelled by incorporating beliefs about the intentions or about the (kindness of the) type of the other person into the individual's utility function. We will return to these models in the next section. Here, we would like to 
emphasize that in these revisions of the homo economicus model, only stable other-regarding preferences have been accounted for, which show no time dependency. Furthermore, there is hardly any serious attempt to explicitly deal with the affective processes involved. ${ }^{1}$ This brings us to our discussion of affective social ties, where both these aspects of existing models will be challenged.

To explain how social interactions can influence economic interactions through the development of affective ties, we need to become more specific about the notion of a social tie (a formal representation is given in the next section). Basically, a social tie refers to a caring about the interests of a specific other person, based on feelings experienced while interacting with that other person. Sentiments are the affective component of interpersonal attachments and are considered to be a key element of a social tie (Baumeister and Leary, 1995; see also Granovetter, 1973). Feelings that individuals have with respect to specific others are related to the extent they care about the welfare of those others. The more they care in a positive way, the stronger the affective bond and 'we' feeling is supposed to be. However, it is important to note that a social tie is not simply determined by the weight that an individual attaches to the welfare of another person.

In general, if positive or negative sentiments are maintained towards others, a social tie can only be said to exist if the weight attached to this specific other's well-being differs from the weight given to the well-being of a 'generalized other (van Dijk and van Winden, 1997).' Furthermore, the strength and the valence of a tie are supposed to depend on the interaction between the individuals concerned, which can be experienced as more or less beneficial or harmful. It is the accumulated affective experience that is taken to matter for the sign and size of the weight attached to the specific other's interests. In this respect, a social tie is like a capital good (a stock variable), built up through investments over time. This makes the development of a social tie inherently dynamic and its strength subject to change. In this process, differences in personality are likely to play a role. Individual differences in tolerance, rationality, altruism, or emotionality may be crucial for the speed with which positive or negative ties develop, and their mutuality (symmetry).

\subsection{Social ties: A formal model}

In this section we present a formalization of social ties based on van Dijk and van Winden (1997), in the sequel referred to as the vDvW-model. An important advantage of formalization

\footnotetext{
${ }^{1}$ An exception is Loewenstein and O'Donoghue's (2007) dual-system model of altruism.
} 
is that it enables the development of rigorous theory and a coherent framework for testable hypotheses. Its relevance will be illustrated in the context of the voluntary provision of a public good.

A public good is characterized by the fact that no one can be excluded from its consumption while, in addition, its consumption by someone does not rival with the consumption by someone else. A classic example concerns the defence of a country against external aggressors. However, here, we are more interested in local public goods, like for small communities, neighborhoods, social networks or groups. Relevant examples are the provision of security, a healthy, clean or pleasant environment, common information, or the establishment and maintenance of social norms (through sanctions).

The following simple public good game captures the essence of the voluntary provision of a public good. Suppose there are two players, $A$ and $B$, both endowed with an amount of money of $y$ euros. The money can be spent on private goods and a public good. Let $j$ 's contribution to the public good be denoted by $g_{j}$ (with $j=A, B$ ). Normalizing the price of both the private and the public good to one, the consumption of private goods by $j$, denoted as $x_{j}$, equals: $x_{j}=y-g_{j}$, while the consumption of the public good, indicated by $g$, equals $g=g_{A}+$ $g_{B}$ for both players. The welfare, or utility, derived from the consumption of $x_{j}$ and $g$ is denoted by $U_{j}\left(x_{j}, g\right)$. For illustration, suppose that both players have the same linear utility function: $U_{j}\left(x_{j}, g\right)=x_{j}+m g\left[=y-g_{j}+m\left(g_{A}+g_{B}\right)\right]$, where $m$ stands for the marginal per capita return on public good contributions. Typically, it is assumed for these games that $0<m<1$ and $\mathrm{nm}>$ 1 , with $n$ the number of players. Thus, in our case, let $2 m>1$ and assume that both players have to decide only once (one-shot game). Then, it is easily seen that a rational and selfish (own utility maximizing) player will not contribute to the public good ( $g_{j}=0$, leading to a utility of $y$ ), even though both players would be better off if they would contribute all their money $\left(g_{j}=y\right.$, rendering a utility of $2 m y$, which is larger than $y$ ). Whatever the other player is expected to do, it is always in one's (selfish) interest not to contribute. More generally, the private provision of public goods seems to be haunted by a 'free-riding' problem, in the sense that all want to benefit from the contributions by others without putting an own effort into it which is adequate from a social point of view (that is, taking the benefits for others into account).

According to the general standard model of public goods (see Bergstrom et al., 1986), the welfare losses to a social group from free riding tend to become larger the bigger the group. ${ }^{2}$ Moreover, generally, the equilibrium public good level turns out to be invariant to the distribution of the endowments (income) and also to an income-tax financed public provision

\footnotetext{
${ }^{2}$ In the standard model the individually optimal contribution level need not be zero (but falls short of the socially optimal level).
} 
of some of the good. In the latter case, public provision simply replaces (crowds out) private provision, one for one. Theoretically, socially better outcomes can be obtained if the game is not one-shot, but repeatedly played over an infinite or uncertain time span, basically because players (may) perceive sufficient opportunity to punish uncooperative behavior (see e.g. Fudenberg and Tirole, 1991). In case of a finitely repeated game, with a known fixed ending, larger contributions can be sustained if the likelihood exists that some players (for whatever reason) are cooperative but will negatively react to free-riding (like tit-for-tat players, see Kreps et al., 1982). In that event, even a selfish player might want to build up a reputation for being cooperative, for some time. However, evidence from laboratory experiments shows that substantial contributions occur even in a one-shot linear public good game, like the one discussed above, or in the last round of such a game, where zero contributions are predicted (for a survey, see Ledyard, 1995; see also Sadiraj, 2007). To explain these 'anomalous' experimental findings, over the last decade or so several models have been proposed that incorporate some kind of other-regarding preferences (see the previous section). These preferences may relate to an interest in the distribution of outcomes (like altruism or inequity aversion) or to reciprocity based either on the (un)kindness of other players' behavioral intentions (e.g., fairness) or the type of the other players (e.g., selfish, altruistic, or spiteful). ${ }^{3}$ For example, it is easy to see that even in a one-shot linear public good game, sufficiently inequity-averse individuals may contribute to the public good if others contribute as well.

Three important characteristics of these new models are that they (1) assume stable other-regarding preferences; (2) do not specify any emotional mechanisms that are, at least implicitly, referred to (as in intention-based models); and, (3) focus on static equilibria. The vDvW-model differs in these respects because of its focus on affect as a driving factor of other-regarding preferences and its explicitly dynamic nature. The model concerns a finitely repeated two-person (non-linear) public good game. For notational convenience, using the notation introduced in the example above, we will focus on player $A$ in the game and leave out the time index. As argued in the previous section, the affective component is taken to be a key element of a social tie. The feelings a person (consciously or unconsciously) experiences with respect to the specific other in a tie are related to the extent s/he cares about the well-being of that specific other person. Staying close to traditional economic modelling this is formalized through an interdependent utility function

$$
V_{A}=\ln U_{A}+\alpha_{A} \ln U_{B}
$$

\footnotetext{
${ }^{3}$ Regarding outcome-based models, see Fehr and Schmidt (1999), Bolton and Ockenfels (2000). For intentionbased models, see Rabin (1993), Dufwenberg and Kirchsteiger (2004). For mixed models, see Charness and Rabin (2002), Falk and Fischbacher (2006). Levine (1998) presents a 'types' model.
} 
and similarly for $B$, where $U_{j}\left(x_{j}, g\right), y_{j}=x_{j}+g_{j}(j=A, B)$, and $g=g_{A}+g_{B} .{ }^{4}$ Furthermore, the weight $\alpha_{A}$ attached to the utility of $B$ represents $A$ 's tie with $B$; that is, the valence and the intensity of the sentiment that $A$ experiences with respect to $B$. Mutatis mutandis, the same holds for $\alpha_{B}$. Based on empirical evidence (Goeree et al., 2002; Liebrand, 1984; Sawyer, 1966), it is assumed that $-1<\alpha_{j}<1(j=A, B)$. Note that $B$ need not necessarily maintain a similar tie with $A$; that is, $\alpha_{A}$ need not be equal to $\alpha_{B}{ }^{5}$

Let us focus first on some stark cases when $\alpha_{j}$ is fixed. If $\alpha_{j}=0$, we are back to the standard economic model with selfish preferences. If $\alpha_{j} \rightarrow 1$, approximately, an equal weight becomes attached to both own and other's well-being, inducing fully cooperative behavior (efficiency). In sharp contrast, if $\alpha_{j} \rightarrow-1$, behavior becomes maximally uncooperative, inducing a minimal contribution level. Consequently, the existence of social ties can dramatically influence the private provision of a public good. Furthermore, with fixed social ties, government provision financed through an income tax would lead to a one-for-one crowding out of private provision, as in the standard model without social ties. Interestingly, some experimental support has been provided for the predictive power of the (log-linearized) Cobb-Douglas specification of $V_{A}$ represented by (1) in explaining contributions in (one-shot) linear public good games (Goeree et al., 2002). ${ }^{6}$ In addition, this study finds substantial heterogeneity of $\alpha_{j}$ across individuals, with estimates ranging between -0.5 and +0.5 . Cox and Sadiraj (2007) show that this type of model can explain several stylized facts regarding lastround contributions in linear public good games (where reputation and future reciprocity cannot play a role), in contrast with inequity aversion models.

As mentioned above, existing models of other-regarding preferences are typically static, not allowing for any intertemporal effects. ${ }^{7}$ Although such preferences may be genetically and/or culturally determined (via the instilment of norms), the vDvW-model focuses on a mechanism that is intrinsically dynamic and non-strategic, involving autonomic affective responses in the limbic system of the brain. Based on (social) psychological findings ${ }^{8}$, this

\footnotetext{
${ }^{4}$ Without loss of generality, we use here a logarithmic transformation of the multiplicative Cobb-Douglas specification in the vDvW-model. Note furthermore that if $V_{B}$ would be substituted for $U_{B}$ in eq. (1) the model's results mentioned below would not be affected in a qualitative sense.

${ }^{5}$ For simplicity, we neglect for the moment the possibility of a general attitude towards other people, which is to be distinguished from a social tie concerning a specific other person. See the next subsection.

${ }^{6}$ Cox et al. (2007) apply a (CES) generalization of this specification to the data sets of several experimental studies concerning a variety of games (other than public good games). Their estimates show that in most cases ( 5 out of 7) a Cobb-Douglas specification cannot be rejected. For a similarly specified model incorporating emotions, see van Winden (2001).

${ }^{7}$ This also holds for the model of Cox et al. (2007) where $\alpha$ (the 'emotional state') is supposed to depend on a reciprocity variable (related to payoffs) and relative status.

${ }^{8}$ See, e.g., Homans (1950), Frijda (1986), Coleman (1990), and the wealth of studies surveyed in Baumeister and Leary (1995).
} 
model assumes that ties develop as an unconscious by-product of prolonged interaction which generates positive (negative) sentiments if valued positively (negatively), and that they may decay over time. In the context of a public good game, the valuation of the interaction is likely to depend on the contributions to the public good. In the model this is captured for $A$ by the 'impulse':

$$
G_{A}=g_{B}-\varepsilon_{A} g_{A}
$$

and similarly for $B$, where $\varepsilon_{A}$ reflects $A$ 's tolerance or reference level regarding $B$ 's contribution. For example, if $\varepsilon_{j}=O(j=A, B)$, then any contribution by the other player is positively valued, whereas it should at least match $j$ 's own contribution if $\varepsilon_{j}=1$. Taking into account the possibility of attrition, the development of a tie over time is formalized for $A$ by the following differential equation:

$$
d \alpha_{A} / d t=f_{A}\left(G_{A}, \alpha_{A}\right)
$$

and similarly for $B$. Figure 1 presents a phase diagram of equation (3), assuming a diminishing marginal impact of the impulse:

Take in Figure 1

If ties do not decay over time, then stationarity $\left(d \alpha_{A} / d t=f_{A}=0\right)$ is compatible with any $\alpha_{A}$ if the impulse $G_{A}$ is zero (horizontal part of dashed line $b$ ), whereas for positive (negative) values of the impulse the tie grows to its upper (lower) bound of $1(-1)$. With attrition, the upward sloping solid line $a$ shows the level of the impulse $G_{A}$ required to compensate for the decay such that a particular value of $\alpha_{A}$ can be sustained. Specifically, note that a sustained impulse 
$G_{A} \neq 0$ is required for $\alpha_{A} \neq 0$. To analyze the dynamics of tie formation, the vDvW-model makes the simplifying assumption that individuals are myopic. This implies that they do not take into account the potential impact of their contributions on their own future feelings and the feelings of others towards them. Although perhaps not completely realistic, this assumption finds some empirical support in the evidence that people show a tendency to underweight their own and others' future emotions (Loewenstein, 1996; Loewenstein and Schkade, 1999). As a consequence, the dynamics can be modeled as a sequence of contribution decisions connected by the development of the tie over time. To illustrate, we assume that players are identical (and $\left.0<\varepsilon_{j}<1\right) .{ }^{9}$ Figure 2 shows the phase diagram.

Take in Figure 2

For explanation, suppose we have a negative value of $\alpha_{A}$. Decay over time would make $\alpha_{A}$ less negative. For stationarity, that is, to keep $\alpha_{A}$ from becoming less negative, this decay effect needs to be offset by a sufficiently negative value of $G_{A}$, requiring that $A$ 's contribution is larger than $B$ 's (since $\varepsilon_{A}<1$; see (2)). But, this implies that $\alpha_{B}$ would have to be more negative than $\alpha_{A}$, which explains why the $A$-curve (where $f_{A}=0$ ) is located below the dashed line in the $3^{\text {rd }}$ quadrant of the diagram. Similarly, for $\alpha_{A}=0$ stationarity demands that $G_{A}=0$, which again implies that $\alpha_{B}$ would have to be smaller than $\alpha_{A}$, and negative. When $\alpha_{A}$ becomes positive, $G_{A}$ must also be positive to compensate for the attrition (which would now decrease the value of $\alpha_{A}$ ). Consequently, for stationarity (see again the $A$-curve) $\alpha_{B}$ increases and switches sign. As $\alpha_{A}$ becomes more and more positive, $\alpha_{B}$ must become larger than $\alpha_{A}$ at some point, due to the assumed declining marginal impact of larger values of $G_{A}$. Because individuals are assumed to be identical, the $A$-curve and the $B$-curve (where $f_{A}=0$ and $f_{B}=0$, respectively) are symmetric and cross where $\alpha_{A}=\alpha_{B}$. The arrows in the diagram show the

\footnotetext{
${ }^{9}$ Furthermore, an interior equilibrium, with $g_{j}>0$, is assumed if $\alpha_{j}=0$.
} 
direction of movement of the ties $\left(\alpha_{A}\right.$ and $\left.\alpha_{B}\right)$ in that particular region of the diagram. Eventually, one will end up in this case at the intersection of the two solid curves.

Some of the main results of the vDvW-model, focusing on the impact of differences in income and preferences for public and private goods, are the following. First of all, a unique social ties equilibrium exists. ${ }^{10}$ With equal preferences and incomes, the ties are symmetric and positive $\left(\alpha_{A}=\alpha_{B}>0\right)$, boosting the voluntary provision of the public good. In case of different preferences or income levels, the ties are asymmetric $\left(\alpha_{A} \neq \alpha_{B}\right)$ and the one with the lower value may be negative, in which event contributions are lowered, against one's own direct interests, to hurt the person concerned. Furthermore, with different incomes, the provision level of public goods may be lower than the level derived from the standard model due to the potential development of negative ties.

In contrast with the invariance result of the standard model of public goods, in case of social ties, government intervention need no longer be neutral with respect to the provision level of the public good. If some of the public good is provided by the government (and financed by an income tax), the total provision level may go down, because of a crowding out of intrinsic motivation through a negative effect on social ties. On the other hand, for similar reasons, government intervention can have a positive impact on the provision of public goods if a community is characterized by negative ties or facing substantial mobility or migration which breaks up existing networks. Also, note that a reduction in public provision will not immediately be taken over by private provision (if at all), because the formation of ties takes time.

\subsection{Social ties: Evidence from the lab}

In this section we present some behavioral experimental support for the social ties mechanism formalized by the vDvW-model. The tool used in these behavioral experiments to measure social ties is based on the psychological 'Ring-test of social value orientation (Liebrand, 1984).' In this test each participant is randomly coupled with an anonymous other participant, and has to choose repeatedly between two 'self-other' payoff combinations. Each such combination allocates a positive or negative number of points (to be exchanged for real money at the end of the experiment) between the decision-maker and the participant $\mathrm{s} / \mathrm{he}$ is matched with. All payoff combinations lie on a circle with the origin as center (which explains the name

\footnotetext{
${ }^{10}$ Because van Dijk and van Winden (1997) prove that the equilibrium of their model is locally stable (based on the Jacobean of the system at its equilibrium), in general, convergence is (only) assured for 'small' departures from the equilibrium.
} 
of this test), with on the horizontal axis points allocated to the decision maker him- or herself (Self) and on the vertical axis points allocated to the other person (Other). Each allocation pair can be seen as a vector. Figure 3 presents an example. Adding all the choices of a participant renders an aggregate vector. The angle of this vector with the horizontal axis provides a measure of the extent to which this participant cares about a 'generalized other,' that is, his or her 'social value orientation'. The predictive validity of people's social value orientation has been shown by many studies (see e.g. Rusbult and van Lange, 1996).

Take in Figure 3

However, a tie refers to a specific other, not a generalized other. Therefore, to measure a social tie van Dijk et al. (2002) applied the test twice: once before social interaction, and a second time after the interaction. In the second case, the participant is no longer linked with a randomly selected other but with the participant s/he interacted with. The sign and the size of the difference in the aggregate vectors (angles) thus determined, respectively, represent the valence and the strength of the social tie established through the interaction. Without correcting for social value orientation - measured by the angle of the vector obtained from the first test the angle from the second test would reflect the more general sentiment of an individual with respect to the specific other interacted with. ${ }^{11}$ Applying this procedure in a repeated two-person nonlinear) public good game experiment ${ }^{12}$, they obtained the following results. First of all, they found a mean angle of the first Ring-test equal to $3^{\circ}$, with a large majority (95\%) of the individual angles being located between $-45^{\circ}$ and $+45^{\circ}$. This implies that the absolute weight

\footnotetext{
${ }^{11}$ By applying this procedure to a control group, which faced an individual decision task without social interaction between the two tests, van Dijk et al. (2002) found the Ring-test to be a reliable test also in this context.

${ }^{12}$ In this experiment each participant, randomly matched with another participant, received an endowment of 10 markers to be allocated to a private account (with a monetary payoff of $28 * i-i^{2}$ cents for $i$ markers) and a public account (with a fixed payoff of 14 cents per marker); in addition there was a fixed cost of 110 cents. This game was repeated for a fixed number of rounds, with the same partner. Assuming rational and selfish players, the game has an interior Nash-equilibrium where 7 markers are put in the private account, and the remainder of the endowment is put in the public account (for any endowment larger than 7), whereas contributing all markers to the public account is group optimal (efficient).
} 
attached to the Other's payoff was almost never larger than 1 (providing some additional empirical support for the plausibility of the assumption that $-1<\alpha_{j}<1$ ). Secondly, the social value orientations thus measured appeared to be correlated with individual contributions to the public good, particularly in the beginning of the interaction, confirming the validity of this measure. Thirdly, individuals typically responded to an increase (decrease) in the contribution by the partner with an increase (decrease) in their own contribution. This reciprocity can be interpreted as providing evidence of a continuous development of social ties (with sentiments being correlated with observed contributions), but it may also (partly) reflect some kind of strategic behavior (like conditional cooperation, see Keser and van Winden, 2000). Fourthly, using earnings in the public good game as an indicator of successful interaction (as they are positively related to the contributions by the partner), a clear impact on the angle of the second Ring-test was found, given the individual's initial angle (social value orientation); see table 1.

Table 1. Linear regressions with angle from second Ring-test as dependent variable and, as independent variables, social value orientation (angle from first Ring-test) and earnings in the last five periods of the public good game (van Dijk et al., 2002).

\begin{tabular}{|lrrrrr|}
\hline & $B$ & SE $B$ & Beta & \multicolumn{1}{c}{$t$} & Sign. $t$ \\
\hline Social value orientation & 0.715 & 0.141 & 0.564 & 5.056 & 0.000 \\
Earnings period 21-25 & 0.048 & 0.019 & 0.283 & 2.536 & 0.015 \\
Constant & -33.074 & 14.661 & & -2.256 & 0.029 \\
Multiple R: 0.712 & & & & & \\
Adjusted R ${ }^{2}$ : 0.484 & & & & & \\
\hline
\end{tabular}

In this case, the second Ring-test was applied unexpectedly after 25 periods of play (out of a total of 32 periods). Similar results were obtained in an experiment with the second test being applied at the end, after the same number of periods. This suggests that ties are developed continuously. Also, different measures of success did not qualitatively affect the findings. ${ }^{13}$

Sonnemans et al. (2006) extended the experimental study of van Dijk et al. (2002) to a similar public good game with four instead of two players. To avoid an excessive time consumption by the second Ring-test (unexpectedly applied after 25 periods), where now each participant would have to make multiple (in fact 32) self-other payoff allocation decisions concerning, successively, each of the three partners in the game, they applied a simpler technique: the Circle-test. In the Circle-test, participants have to make a self-other payoff

\footnotetext{
${ }^{13}$ Another interesting observation is that in an experiment with unequal endowments (with one player having 8 markers and the other player 12 markers) they found that the contributions by participants with the higher endowment (in excess of the Nash-equilibrium prediction) were significantly less, in line with the predictions of the vDvW-model.
} 
allocation only once by clicking on a circle, like in figure 3. With groups, this technique is much more convenient, although it is obviously noisier due to the single decision that is to be made. Their main findings are the following: On average, it turns out that contributions are quite similar to what is observed in the two-player game. However, a large variance is observed between groups, with some groups being highly successful, and others failing strongly in the provision of the public good. Table 2 shows the outcomes of the different attitude (Circle-test) measures. Almost all participants showed a non-negative social value orientation, with almost half of them maintaining a positive attitude towards a generalized (randomly selected and anonymous) other. As observed for the two-player game, almost always the first Circle-test angle is between $-45^{\circ}$ and $+45^{\circ}$ (98\% of the cases). Sentiments towards the specific others interacted with - measured by the second Circle-tests, after the game - turn out to be more negative. Finally, in terms of social ties - measured by the difference in the angles derived from the second and the first Circle-tests - an almost equal percentage is observed for positive and negative ones. About half of the participants with a neutral (zero) first angle developed at least some tie with the others interacted with.

Table 2. Attitudes of participants towards others (Sonnemans et al., 2006).

\begin{tabular}{|llllc|}
\hline & Positive & Neutral $^{*}$ & Negative & Total \\
\hline $\begin{array}{c}\text { Social value orientation } \\
\text { (first Circle-test) }\end{array}$ & $26(47 \%)$ & $28(51 \%)$ & $1(2 \%)$ & 55 \\
$\begin{array}{c}\text { Sentiments towards specific } \\
\text { other (second Circle-test) }\end{array}$ & $80(48 \%)$ & $73(44 \%)$ & $12(8 \%)$ & 165 \\
$\begin{array}{c}\text { Social ties } \\
\text { (difference in Circle-tests) }\end{array}$ & $41(25 \%)$ & $76(46 \%)$ & $48(29 \%)$ & 165 \\
\hline
\end{tabular}

* Neutral attitudes correspond to Circle-test angles between $-5^{\circ}$ and $+5^{\circ}$.

In support of the vDvW-model it is further found that differences in the second Circle-test angles with respect to specific others are correlated with the differences in their contributions, which suggests that during the game participants have built bonds with specific group members, rather than a general 'group cohesion'. Also, responses in the debriefing questionnaire to the question of whether one would want to continue the game with a specific partner (asked separately for each of the three partners) are strongly correlated with sentiments and ties. This speaks for the validity of the social ties measure. Interestingly, mutually positive or negative ties are observed in only $15 \%$ of the cases (mutual neutrality in $19 \%$ of the cases). Apparently, even an environment in which participants have equal endowments and payoff structures, individual differences in social value orientation and behavioral response patterns 
result in complex dynamics, mostly generating asymmetric ties. These results would seem to qualify the suggestion borne out by the 'minimal group paradigm' and social identity theory (Tajfel and Turner, 1986; Taylor and Moghaddam, 1994) that social cohesion is easily established. ${ }^{14}$

Up to now, the support for the vDvW-model of social ties has been only indirect in the sense that no direct evidence has been provided for the affective mechanism assumedly underlying social ties. ${ }^{15}$ A recent experimental study by Brandts et al. (2007) fills this gap. One of their experiments concerns a repeated social dilemma game, where each of the two players can either choose to cooperate or not to cooperate. As in a linear public good game it is a dominant strategy in the stage (one-shot) game not to cooperate, even though they would obtain a higher payoff if both would cooperate. The authors used the Circle-test before and after the interaction, to measure social value orientation and the ex post sentiment towards the other player. In addition, after the interaction but before the second Circle-test, they measured the positive and/or negative emotions participants experienced (like anger, joy, guilt, etc.) and with what intensity, using self-reports. ${ }^{16}$

Their main findings are, first, that interaction success (in terms of earnings) is clearly positively (negatively) correlated with the positive (negative) emotions participants experienced after the interaction. However, it turns out that interaction success does not help much to explain sentiment towards the partner as measured by the second Circle-test. In a regression model with social value orientation and interaction success as other explanatory variables, only emotions show a clear impact (as does the individual's social value orientation) and significantly improve the fit of the model. More specifically, guilt and surprise show a positive impact, whereas a strongly negative effect is observed from contempt. Thus, it appears that interaction success triggered (some) emotions, which in turn produced a positive or negative social tie with the individual interacted with. These experimental results indeed suggest that the development of ties is mediated by emotions, as hypothesized in the vDvWmodel.

\section{Towards the neuroeconomics of social ties}

\footnotetext{
${ }^{14}$ The results also plead against inequity-aversion. In only $4 \%$ of the cases positive-negative combinations of sentiments are observed, while such combinations should occur if indeed a participant with large earnings in the game (a free rider) would typically give $(+)$ to a little earning participant (who contributed a lot) and the latter would typically take $(-)$ from the former.

${ }^{15}$ Another important issue that is awaiting investigation is to what extent behavior indeed converges as suggested by the model.

${ }^{16}$ Subjects only learned the nature of a specific part of the experiment once that part started.
} 
The experimental support found for the vDvW-model depends for the affective part on the validity of the self-report measures that were used. Although there is evidence showing that self-reports in economic game experiments correlate with physiological measures of emotionality (see e.g. Ben-Shakhar et al., 2007), there are clear limitations to this often-used technique of measuring emotions. One example is the fact that it relies on consciously experienced feelings and honest reporting. Therefore, it would be interesting to see what evidence can be mustered from modern neuroscientific methods like brain imaging. This would fit into the gradually emerging interdisciplinary field of neuroeconomics (Camerer et al., 2005; Rustichini, 2005; Sanfey et al., 2006). Within this approach, researchers combine traditions from human and animal experimental psychology and cognitive neuroscience with mathematical decision models, often using simple experimental games, like the prisoner's dilemma game ${ }^{17}$ (see Fehr and Camerer, 2007; Sanfey, 2007).

To prepare the grounds for a model-based neural analysis, in this section, after a short reminder of the nature of social ties and a discussion of related constructs, we will review the existing evidence of neural correlates. Several cognitive and affective processes may underlie or be involved in social tie formation, each perhaps playing a role at different moments of the social interaction. Below, the processes that may be relevant for the development of a social tie in a public good game will be evaluated, and we will discuss and speculate on the possible neural bases of these processes and their dynamics.

\subsection{Constructs related to social ties}

An important feature of a social tie is its dynamic stock-variable nature. While social ties are presumed to be nonexistent when individuals meet for the first time, they are taken to develop rapidly during a relatively short period of interaction (minutes to hours). Affective feelings towards the other may start to develop already during the initial moments of social interaction. Whether these affective feelings result in a positive or negative tie will depend on one's appraisal of the other's behavior. If the other's behavior is in line with one's interests, this can be considered as an impulse for the development of a positive social tie. A positive social tie in the two-person public good game exists to the extent that one positively cares about the payoff of the other player in excess of one's care for a 'generalized other.' Formally, this is captured by a weight attached to the other's welfare, which is net of the weight representing one's social

\footnotetext{
${ }^{17}$ A prisoner's dilemma game can be seen as a simple two-player public good game with only two choices available to the players, either to 'cooperate' (equivalent to contributing one's endowment to the public good)) or to 'defect' (not contributing to the public good).
} 
value orientation. A negative social tie develops when the behavior of the other is not in line with one's own interests. A social tie is not necessarily symmetric: one may be concerned about the payoff of the other in the public good game, while the other is not concerned (as much) about your welfare.

Of the numerous concepts that are used to describe social behavior in psychology, the notions of empathy and sympathy seem of particular relevance here. Empathy, which roughly refers to the ability to "put oneself into another's shoes," is commonly considered to have three characteristics (Lamm et al., 2007): (1) affective sharing, that is, an affective response to another person which may entail sharing that person's (imagined) emotional state; (2) perspective taking, involving a cognitive capacity to take the other person's perspective; and (3) cognitive appraisal, involving monitoring mechanisms that keep track of the origins (self vs. other) of the experienced feelings. The third property refers to the generally accepted view that empathy requires a link, but no confusion, between the self and other (Decety and Hodges, 2006). This property seems to dissociate empathy from the concept of a (positive) social tie, which involves a kind of merger between the self and the other into some shared identity, accompanied by a ('we') feeling of bonding.

Empathy further appears to be subject to contextual appraisal and modulation, and supposedly exists because it facilitates social communication and helps forecast other people's needs and actions (de Vignemont and Singer, 2006). These properties are clearly important for the development of social ties. However, negative experimental findings concerning the presumed link between empathy and altruism (the capacity to act selflessly) point again at an important difference with (positive) social ties. According to Maner et al. (2002; Cialdini et al., 1997), the relation with helping put forward in the literature appears to be due to two concomitant non-altruistic factors: perceived oneness and experienced negative affect (which in turn mediates helping). Oneness (merged identity with the person in need) stimulates emphatic concern as well as helping, which may further function as an emotional signal of oneness.

Consequently, while empathy can be regarded as an important factor in the development of social ties, it particularly differs from the latter construct in the motivational role that the other plays. During social tie development, the cognitive capacity to understand the mental state of the other plays an important role as the capacity of perspective taking is accompanied by feelings of attachments (e.g. friendship, familiarity and similarity, see also Cialdini et al., 1997) or aversion. Taking the perspective of the other while at the same time attending to the other's behavior can lead to an empathic affective response (which does not require any direct emotional stimulation). However, empathy is not identical to a social tie as 
perceived here, because the merger of self and other in some shared identity is absent in empathy, where the self and the other remain separate entities.

The concept of sympathy seems more closely related to a (positive) social tie. Most scholars seem to agree that sympathy is an affective response that frequently stems from empathy and consists of feelings of concern for another person. According to Decety and Chaminade (2003), sympathetic concern indicates that there is affinity, agreement, and association with someone. Anything that affects oneself is supposed to similarly affect the other. This is in line with our description of a (positive) social tie. To the extent that interactions between individuals are experienced as positive (assumedly fostering a positive social tie), feelings of affinity, agreement, and association are likely to grow as well. However, it is important to note that the opposite may also occur; namely, negatively experienced social interactions (inducing feelings of antipathy, dislike, and dissociation with the other) may foster the development of a negative tie.

Interestingly, the founding father of economics as a science, Adam Smith, referred to (habitual) sympathy as an underlying factor driving affective (kin and non-kin) relationships representative of social ties (Smith, 1759). Furthermore, in his view, social ties abound even in competitive business environments, as illustrated by the following quote (op. cit., p.224): "Colleagues in office, partners in trade, call one another brothers; and frequently feel towards one another as if they really were so. Their good agreement is an advantage to all (...)". ${ }^{18}$

\subsection{Neural correlates of constructs related to social ties}

With respect to the dynamic formation of social ties, the key features of empathy and sympathy appear to be perspective taking, cognitive appraisal, and concern about the other's well-being. The first two components encompass factors such as 'mentalizing' and 'theory of mind' and entail the processing of norms like fairness. The latter component may encompass processes related to altruism, generosity, reciprocity, oneness, and so on. Below, we will selectively review the literature on the neural bases of each of these three components.

\subsubsection{Perspective taking - What would the other think?}

Especially during the first rounds of the public good game, the capacity to take the perspective

\footnotetext{
${ }^{18}$ Later, Edgeworth (1881) called a parameter similar to our $\alpha$ a "coefficient of effective sympathy", in a footnote (p. 53) in his classic book Mathematical Psychics.
} 
of the other is essential for both players. This capacity (often referred to as 'mentalizing') enables one to explain and predict the emotions and actions of the other. This cognitive capacity of perspective taking is also known as 'theory of mind.' Having a theory of mind (ToM) means that one recognizes that the other has a different perspective of the world than oneself, and that his or her behavior may be determined by different goals than one's own. Understanding the actions of someone facilitates the effective development of a social tie.

Functional neuroimaging has been invoked to help identify neural mechanisms underlying ToM. Evidence from such studies highlights the role of a number of areas in the brain (e.g. Gallagher and Frith, 2003; Saxe, 2006). However, most of these studies did not involve actual social interactions. Instead, in these experiments participants were asked to reason about the mental states of characters that were presented in stories, cartoons, or photographs (Baron-Cohen et al., 1999; Brunet et al., 2000; Gallagher et al., 2000). Only few studies examined the neural correlates of mentalizing in participants who were immersed in actual social interactions, or in which participants believed they were interacting with a real human being while in actuality responses of the partner were generated and administered by a computer algorithm (Gallagher et al., 2002; McCabe et al., 2001; Rilling et al., 2004a). These studies show that two brain areas are particularly important for mentalizing in fictive situations and are associated with ToM in actual social interactions. These brain areas are the anterior paracingulate cortex (APCC) and the posterior superior temporal sulcus (pSTS).

\section{Anterior paracingulate cortex}

McCabe et al. (2001) reported dorsomedial prefrontal regions to be activated when subjects were playing a 'trust game' with a human partner. In this two-person sequential game, the first mover could decide to either end the game (which leads to a fixed equal payoff to both players) or to let the other player (the trustee) choose between an option where both players would be better off and an option where only the second player would benefit but the first player would lose, compared to their payoffs when the game is ended by the first mover (the trustor). Of most interest, McCabe et al. (2001) observed that the APCC is activated when trustees make cooperative decisions, that is, when they choose not to be selfish but go for the option where both players benefit. The authors suggest the APCC to be an "active convergence zone that binds joint attention to mutual gains with sufficient inhibition of immediate reward gratification to allow cooperative decisions".

Krueger et al. (2007) replicated and extended this finding using a similar, albeit nonanonymous, sequential reciprocal trust game in which partnership building and maintenance became essential. The APCC was shown to be critically involved in building a trust 
relationship by inferring another person's intentions to predict subsequent behavior.

In a study by Rilling et al. (2004a), the APCC is also reported as an important neural correlate of ToM. In their experiment the APCC was activated when participants were playing a series of a one-shot ultimatum game ${ }^{19}$ and a series of a one-shot sequential prisoner's dilemma game. In both games, participants observed their partner's decision before they had to respond (with either acceptance or rejection of the offer in the ultimatum game, and with cooperation or defection in the prisoner's dilemma game). The decision a participant makes depends on how $\mathrm{s} /$ he interprets the action of the partner.

\section{Posterior superior temporal sulcus}

In addition to the APCC, Rilling et al. (2004a) also found the pSTS to be more active when participants believed they were playing these games against a human being instead of a computer. Studies that examined the ToM ability by asking participants to mentalize about characters (instead of real human beings) consistently activated the STS area (Brunet et al., 2000; Castelli et al., 2000; Gallagher et al., 2000). It has been suggested that the role of the STS is related to an initial analysis of social cues to provide a signal of the intention of another individual (Allison et al., 2000).

\subsubsection{Appraisal - Is the behavior of the other in line with one's own interests?}

Some people may readily develop a social tie, while others need more time to develop affective feelings towards the other player in the public good game. Whether one cares about the other's concerns will depend on the perceived importance of the other person's behavior for one's own concerns, including internalized social norms (Montague and Lohrenz, 2007). If the other behaves according to one's social norms, then this may function as an impulse for the development of a positive social tie. Fairness norms, in particular, play a role in the modulation of social relations (Dawes et al., 2007). The implementation of fairness norms in the public good game leads one to expect the other to reciprocate investments in the public good. In the case that a player plays unfairly (i.e., does not contribute to the public good), this may indulge negative feelings in the other towards this player. Brain areas that play a role in the implementation of fairness-related behavior are discussed below.

\footnotetext{
${ }^{19}$ An ultimatum game is a two-player game where one player gets the opportunity to make an offer regarding the division of an amount of money given by the experimenter and the other player can either accept or reject. In the latter case both players get nothing (Güth et al., 1982).
} 


\section{The striatum}

The striatum appears to be involved in monitoring the other's decision to reciprocate cooperation or not, presumably in order to facilitate learning who can and who cannot be trusted as a social partner. In a prisoner's dilemma game, each participant probably makes an estimate of the likelihood that his or her cooperation will be reciprocated, even though this estimate is unlikely to be correct. The discrepancy between the actual choice of cooperation ( 0 or 1) and the probability with which cooperation by the other player is predicted is the reward prediction error. Positive reward prediction errors (as elicited by reciprocated cooperation) have been found to correlate with increased activity in the striatum, while negative reward prediction errors (elicited by unreciprocated cooperation) were associated with a decreased activation (Rilling et al., 2002; Rilling et al., 2004b). Thus, the striatum appears to register social prediction errors (and perhaps encodes the positive feeling garnered by mutual cooperation) to guide decisions about reciprocity (Sanfey, 2007).

King-Casas et al. (2005) found that activity in the caudate nucleus (part of the striatum) was modulated by reciprocity in a multi-round trust game. Benevolent reciprocity (when the trustor is generous in response to a defection by the trustee in the previous round) was associated with greater activity of the caudate nucleus in the trustee's brain than malevolent reciprocity (when the trustor repays the generosity of the trustee with selfishness). These results confirm the suggestion that the striatum registers the benevolence of the other's decision and guides decisions about reciprocity. Furthermore, in the beginning of the trust game, the caudate was most active after the decision of the trustor was revealed, but as the game progressed, activity in the caudate shifted its time of occurrence to a time before that decision. Thus, the dynamics of activation patterns in the caudate reveal that as the social interactions progress, the trustee learns to develop intentions to trust or distrust the other player.

\section{Anterior Insula}

Experiments with the ultimatum game suggest that activation seen in the insula reflects one's negative emotional response to 'unfair' offers, that is, offers where one gets less than an evensplit (Sanfey et al., 2003). The insula is a brain region that is often associated with negative emotional states (Calder et al., 2001; Damasio et al., 2000). In the study by Sanfey et al. (2003), activity in the anterior insula is greater when participants in the ultimatum game are offered unfair instead of fair splits of money. Furthermore, activity in this brain area was predictive of the decision to reject unfair offers, with rejections associated with significantly 
higher activation than acceptances. The anterior insula has been suggested to encode the social interaction as aversive, serving to discourage trust and positive responses (Sanfey, 2007), or, alternatively, to encode the degree of unfairness of the other's offer, that is, how much the offer differs from some norm (Montague and Lohrenz, 2007).

\section{Anterior cingulate cortex}

Activity in the anterior cingulate cortex (ACC), a brain area involved in processing signals that register as a risk (Ridderinkhof et al., 2004), is also involved in the decision to accept or reject unfair offers in the ultimatum game (Sanfey et al., 2003). The ACC is known for its role in cognitive conflict and its activation may reflect the tension between cognitive and emotional motivations when persons consider rejecting an unfair offer. Using an iterated trust game, Tomlin et al. (2006) found two distinct agent-specific response types in the ACC, one consistent with decisions that signal "me" and another consistent with decisions that signal "not me".

\section{Dorsolateral prefrontal cortex}

Besides the influence of emotional states on the decision to accept or reject unfair behavior (as reflected by insular activity), cognitive processes are also of importance in this decision. Sanfey et al. (2003) observed that the dorsolateral prefrontal cortex (DLPFC), a region usually linked to cognitive control processes such as goal maintenance (Miller and Cohen, 2001), plays a role during the ultimatum game. Possibly, competition between the anterior insula and the DLPFC is important in the decision to accept or reject an unfair offer. Activity in the DLPFC was higher than activity in the anterior insula when participants decided to accept unfair offers, while unfair offers that were rejected showed instead greater activity in the insula than in the DLPFC.

Studies using transcranial magnetic stimulation (TMS) have elaborated on the role of the DLPFC in the decision to accept or reject unfair behavior (Knoch et al., 2006; van 't Wout et al., 2005). These studies suggest that the DLPFC is involved in overriding selfish impulses in order to reject offers that are perceived as unfair. Disrupting brain activity in the DLPFC by the administration of a brief TMS pulse caused a greater number of unfair offers to be accepted in this group of participants compared to the control group. ${ }^{20}$

\footnotetext{
${ }^{20}$ As noted by Knoch et al. (2006), these findings run counter to the interpretation of Sanfey et al. (2003) that the DLPFC is crucial in overriding fairness impulses (to reject unfair offers).
} 


\subsubsection{Beneficial behavior - Care about the other's welfare}

Both processes discussed so far, the ability to reason about one's partner's intentions and the impulse that determines if a social tie may start to develop, are important for the development of a social tie between participants in the public good game. Neural correlates of these processes have been suggested. However, what happens in the brain when one indeed has started to care about the other player?

\section{ACC and insula}

Results of an experimental study with an iterated one-shot trust game by Singer et al. (2006) showed that neuronal activity in the ACC and in the anterior insula are modulated as a function of whether the subjects liked or disliked their partner in the game. In the second part of this experiment, participants observed partners who had played fair and unfair strategies (that is, reciprocated with large and small amounts, respectively) receiving painful stimulation. Unfair players were rated as less likeable than fair players. Activity in pain-related brain areas (the anterior insula and the ACC) was attenuated by the knowledge that an unfair player was in pain. The finding that responses to fair and unfair behavior are related to the affective feelings one has towards another lends support to the notion that brain activity in the public good game may be modulated as a function of a social tie. ${ }^{21}$ In this respect, the activation of the anterior insula might be a case in point. Its putative role in risk prediction (Knutson and Bossaerts, 2007; Kuhnen and Knutson, 2005) and in signaling norm violations (Montague and Lohrenz, 2007) suggests that under the formation of a positive social tie its role in social decisionmaking will diminish ${ }^{22}$, whereas under the formation of a negative social tie it will be more active. The latter is suggested also by the role of anterior insula activation in frustration (Abler et al., 2005).

\section{Orbitofrontal cortex}

Arranging and experiencing mutual cooperation in economic interactions has been related to the reception of reward. Cooperative behavior in an iterated one-shot prisoner's dilemma game

\footnotetext{
${ }^{21}$ In fact, in male participants the effect was accompanied by increased activity in reward-related areas (striatum), which was correlated with an expressed desire for revenge. These findings are suggestive of a negative tie, as these participants appear to experience the loss in well-being of the person in pain as rewarding.

${ }^{22}$ Instead, evidence from studies on maternal and romantic love relationships points at a potentially increasing role of the medial insula in that case (Aron et al., 2005; Bartels and Zeki, 2004). The medial insula is considered to be a pathway for 'limbic touch,' evoking pleasant feelings of touch and regulating affiliative responses.
} 
has been found to elicit increased activity in reward-related areas such as the striatum (caudate nucleus, nucleus accumbens, and putamen), the ventromedial prefrontal cortex (VMPFC), and the orbitofrontal cortex (OFC) (Rilling et al., 2002; Rilling et al., 2004b). These areas receive mesencephalic dopamine projections and play an essential role in the processing of rewards, such as food, drugs, sex, and money (Moll et al., 2005; Schultz et al., 1997; Tanaka et al., 2004). Regarding the OFC, there is general agreement on a medial to lateral functional specialization within the OFC on behavior that is related to reward and punishment. The lateral OFC has been linked to punishment and associated with social aversion (Kringelbach, 2005; Moll et al., 2005). The medial part of the OFC is suggested to be more important for rewardrelated behavior (Kringelbach, 2005). Although the OFC was activated during cooperation in the prisoner's dilemma game, its response was not dependent on the context, that is, whether the partner was a computer or a human being. In contrast, increased activation in the striatum and VMPFC after a cooperative outcome was only elicited when a human partner reciprocated cooperation, but not in the case of a computer partner (or when an equivalent amount of money was simply provided). These results indicate that successful interaction with human partners is particularly rewarding. ${ }^{23}$

\section{Striatum and septal area}

Activation of the striatum is modulated by several factors that might be related to the strength of social ties. For instance, Fließbach et al. (2007) showed that responses in the ventral striatum are modulated by social comparison. Rewards that were equal in absolute magnitude elicited smaller responses in the striatum when the reward was less than that received by a second person. Harbaugh et al.(2007) observed that donations to charity goals elicit activity in the ventral striatum, but more so when these donations were voluntary than when they were mandatory. Moreover, the striatal response to the charity's financial gains predicted voluntary giving.

Delgado et al. (2005) examined how prior social and moral information about someone modulated striatal activity. They replicated earlier findings in that activity in the caudate nucleus differentiated between reciprocated and unreciprocated cooperation in the trust game (cf. Rilling et al., 2004b). However, when information was provided about the character of the partner, either good or bad, this differential response in the striatum between positive and

\footnotetext{
${ }^{23}$ This finding may be related to a positive social tie, because an extra reward is obtained from the presence of a human partner with whom one interacted successfully. Using fMRI with a social interaction simulation task, Güroğlu et al. (2008) find that interacting with friends specifically involves the VMPFC and the nucleus accumbens. In addition, they find friend-specific involvement of the amygdala and the hippocampus, which may indicate the spontaneously greater retrieval of emotionally salient memories in case of the interaction with friends.
} 
negative feedback was absent. This suggests that perceptions of moral character can diminish reliance on feedback mechanisms in an area that is involved in social reward learning.

More generally, the striatum is seen as part of a modality-independent network of reward structures that is specialized to mediate attachment (Bartels and Zeki, 2004, see also above). This network is generally rich in receptors of oxytocin, a neuropeptide that is well-known for its relationship with attachment and caring behavior (Insel and Young, 2001). ${ }^{24}$ Zak et al. (2007) found that participants infused (via nasal administration) with oxytocin exhibited greater generosity in dictator as well as ultimatum games. ${ }^{25}$ Kosfeld et al. (2005), using a similar technique, found a substantial increase in trusting behavior in a trust game, but no difference in the acceptance of financial risks, suggesting an essential role for oxytocin as biological basis for a pro-social approach.

In their reciprocal trust game study, Krueger et al. (2007) observed for non-defectors (who never defected on the partner's decision to trust), after a 'building' stage where the paracingulate cortex was relatively active, that their unconditional trust selectively activated the septal area (relative to defectors) during the subsequent 'maintenance' stage. This brain region, linked to social memory and learning, contains oxytocin receptors and is putatively involved in controlling the release of oxytocin. ${ }^{26}$ Furthermore, behavioral ratings revealed that only non-defector pairs felt closer to each other and ranked themselves as being more of a partner to the other person after the experiment. According to the authors, this brain area may be involved in encoding goodwill. Also, some evidence exists showing that oxytocin can be enhanced by receiving signals of trust in a trust game, which in turn may lead to greater trustworthiness (Zak et al., 2005).

\subsection{Neural bases of social ties: Some speculations}

Based on the findings summarized in the previous subsection, it seems that a social tie can show up in various ways. In general, it may manifest itself in an increased activation in some brain region (like the striatum), in a changing timing and/or location of the activation within some region (like the striatum with learning ${ }^{27}$ ), in the involvement of new regions (like the

\footnotetext{
${ }^{24}$ Oxytocin is also implicated in addiction. There seem to be similar pathways for social attachment and psychostimulants (Insel and Young, 2001).

${ }_{25}$ A dictator game differs from an ultimatum game in that the second mover can only accept what the first player 'proposes'.

${ }^{26}$ From a learning perspective, it is interesting to note that whereas the septal area as well as the pallidum have been found to play a role in early-stage romantic love relationships, the pallidum appeared to gain in importance in relationships of longer duration (Aron et al., 2005; Bartels and Zeki, 2004).

${ }^{27}$ Regarding the former, see King-Casas et al. (2005), and, with respect to the latter, Haruno and Kawato (2006).
} 
septal area, linked to attachment), or a diminished involvement of some regions (like the paracingulate cortex). Regarding the last point, Bartels and Zeki (2004) speak of human attachment as a "push-pull mechanism" that overcomes social distance by deactivating neural networks used for critical social judgment and negative emotions while bonding individuals through the reward circuitry. Therefore, it seems likely that the weight that is attached to the wellbeing of another person is represented by a compound neural network rather than some specific brain area. Nevertheless, some brain regions may be critical, like the amygdala and the VMPFC that appear to be essential for the activation and successful integration of emotionrelated memories (e.g., of sanctions) in the anticipation of future consequences of actions (see e.g. Bechara and Damasio, 2005; Güroğlu et al., 2008).

Although we do not know at this stage what this network precisely looks like, we can speculate regarding its nature, under the usual caveat implied by such speculations. We assume, for simplicity, two players in a public good game who are initially complete strangers to each other (no existing ties), and we neglect any social value orientation (we will return to that later). Furthermore, for expositional reasons, we focus on the development of a positive tie.

Our discussion in the previous subsection suggests three key facets of the development of an affective social tie: perspective taking, appraisal, and care ${ }^{28}$. Particularly in the beginning of the game, players are likely to be engaged with fathoming the situation the other is in and what the other will think. Two brain areas have been particularly associated with this 'mentalizing,' the APCC and the pSTS. Behavioral expectations on the basis of norms or other reference levels may be generated. In terms of the simple ties model presented in section 2 , this might shape the tolerance or reference level $\varepsilon_{A}$ (see eq. (2)). Appraisals of the other's behavior during the game in light of one's concerns (including internalized norms) and adjusting beliefs are important for the further cognitive and affective encoding of the signals extracted from the social interaction. Brain areas expected to be particularly involved in these appraisal processes are related to reward prediction and learning (striatum), norm violations (anterior insula), cognition-emotion conflict (ACC), and cognitive control (DLPFC). In the formal model this facet of tie formation is, as a first approach, represented in a simplistic way by the 'impulse' $G_{A}$. Personality traits (e.g., related to emotionality) may cause a substantial heterogeneity among individuals in the way these appraisals are made and elaborated. Both processes of perspective taking and appraisal, finally, may set in motion a growing appreciation (care) for

\footnotetext{
${ }^{28}$ The neural circuits involved in perspective taking and appraisal will likely involve common areas irrespective of whether the social tie will develop positively or negatively. Below we will speculate on the potentially differential involvement of brain areas in the third phase of positive and negative tie formation.
} 
the concerns of the partner in the game, which is represented in the model by the (stock) variable $\alpha_{A}$ attached to the utility of the other individual. Brain areas presumably implicated once an individual has started to (positively) care about the other individual ${ }^{29}$ are the striatum, the $\mathrm{VMPFC}^{30}$, and the septal area. In the next, concluding section several issues for future research will be indicated.

\section{Concluding remarks}

In this article we have addressed the economic importance, formalization, and the psychological and neural correlates of affective social ties. We hope to have shown the promising nature of this topic and conclude with some important issues for future research.

First of all, it is now important to link up the parameters of formal models of social ties with neural activity, for example, through model-based fMRI studies. In this way, a systematic and empirical data-based approach is obtained that lends itself for the generation of a coherent set of hypotheses and the development of a well-founded neuroeconomics of social ties.

Secondly, a dynamic model of social ties is needed because emotion is all about transition and more related to homeodynamics (behavioral adjustment) than homeostasis (Damasio, 2003). In this respect, the dual-system vDvW-model discussed above seems a good starting point for the study of voluntary public good provision. However, a more flexible model, for example, allowing for some foresight or the influence of moods or personality traits, may be desirable.

Thirdly, because the state of the art in neuroeconomics is such that no definitive answers are to be expected from whichever method or technique one uses, it is important to exploit as many research tools as possible. This includes not only various neuroscientific techniques like TMS, physiological measures (e.g., skin conductance or heart rate), the administration of substances (like oxytocin), or the use of individuals with brain lesions, but

\footnotetext{
${ }^{29}$ We can speculate that the development of negative ties involves several areas. First, as in positive tie formation, the striatum is expected to be involved as it detects unreciprocated cooperation in the trust game (Delgado et al., 2005; Rilling et al., 2004b). Also, increased activity of the striatum was correlated with observed physical pain in a disliked individual (Singer et al., 2006), suggesting a rewarding experience (like 'sweet' revenge), as one would expect in case of a negative tie. Second, as the anterior insula is implicated in signaling norm violations (Montague and Lohrenz, 2007) and in encoding aversive interaction (Sanfey, 2007), it is likely to be more active under the formation of negative social ties, as suggested also by the role of anterior insula activation in frustration (Abler et al., 2005).

${ }^{30}$ A recent study (Jenkins et al., 2008) suggests that the VMPFC is similarly engaged by mentalizing about oneself as by mentalizing about similar others. To the extent that a positive tie makes people feel more similar this finding would add to the role of the VMPFC.
} 
also questionnaires (e.g., for the measurement of traits, particular emotional states or expectations). Furthermore, the simultaneous investigation of interacting brains through hyperscanning may deliver important additional information, for example, in relation to the issue of oneness in case of social ties (Krueger et al., 2007). In the context of social ties, oneness (or 'me-other' merger) would seem to imply that one's own payoff should show up as being similarly rewarding as the other's payoff. On the other hand, the fact that one cares about the other also implies that, when appropriate, one tries to figure out what is best for the other, involving perspective-taking and mentalizing, which means a differentiation between self and even a close other (cf. Heatherton et al., 2006).

Fourthly, among the important (additional) issues to be studied are the impact of the mode and the frequency of interaction. For example, to what extent is interaction with others through political participation to provide a public good different from decentralized provision via voluntary contributions? Apart from the frequency of interaction, factors determining emotional intensity, such as proximity and anonymity, would seem to be important here.

Another interesting issue concerns the equilibration of a social tie. The vDvW-model allows for an equilibrium state with a social tie, where the decay of the tie is just compensated by the impulse. However, if emotion is indeed all about transition and homeodynamics, it is not immediately clear whether an affective tie is compatible with an equilibrium state where nothing unexpected happens. This is not the place to go more deeply into this issue. Note, however, that the incorporation of randomness in the model - which may be appropriate because of the stochasticity in neural firing rates, for example (Glimcher et al., 2005) - would imply some unpredictability of behavior.

Fifthly, what is the relationship, if any, between social value orientation and social ties? To what extent is it simply an aggregate (weighted) representation of one's (past and present) social ties? ${ }^{31}$

Finally, in view of the observed similarities between romantic love and addiction regarding the use of reward structures in the brain, it seems of interest to investigate the (dis)similarities between addiction and different forms of attachment, including social ties. In all these cases, affective impulses (like an investment) are feeding an intertemporal stock variable. On a different and more speculative note, a similar production process seems to take place in case of the internalization of a social norm, where through the application of sanctions (punishments and rewards) a concern or interest is instilled in the individual. Therefore, it might be interesting to include the internalization of norms into this investigation as well.

\footnotetext{
${ }^{31}$ For some empirical support, see Van Lange et al. (1997)
} 


\section{Acknowledgements}

Support by the Netherlands Organisation for Scientific Research (NWO) and the European Union through the research network ENABLE is gratefully acknowledged. We are further thankful to an anonymous referee and participants of the Arne Ryde Workshop on Neuroeconomics (Lund), in particular our discussants Georgio Coricelli and Erik Mohlin, for their useful comments. 


\section{References}

Abler, B., Walter, H. and Erk, S. (2005), "Neural correlates of frustration", Neuroreport, Vol. 16, No. 7, pp. 669-72.

Allison, T., Puce, A. and McCarthy, G. (2000), "Social perception from visual cues: role of the STS region", Trends in Cognitive Sciences, Vol. 4, No. 7, pp. 267-278.

Aron, A., Fisher, H., Mashek, D. J., Strong, G., Li, H. and Brown, L. L. (2005), "Reward, motivation, and emotion systems associated with early-stage intense romantic love", Journal of Neurophysiology, Vol. 94, No. 1, pp. 327-37.

Baron-Cohen, S., Ring, H. A., Wheelwright, S., Bullmore, E. T., Brammer, M. J., Simmons, A. and Williams, S. C. (1999), "Social intelligence in the normal and autistic brain: an fMRI study", European Journal of Neuroscience, Vol. 11, No. 6, pp. 1891-8.

Bartels, A. and Zeki, S. (2004), "The neural correlates of maternal and romantic love", Neuroimage, Vol. 21, No. 3, pp. 1155-66.

Baumeister, R. F. and Leary, M. R. (1995), "The need to belong: desire for interpersonal attachments as a fundamental human motivation", Psychological Bulletin, Vol. 117, No. 3, pp. 497-529.

Bechara, A. and Damasio, A. R. (2005), "The somatic marker hypothesis: A neural theory of economic decision", Games and Economic Behavior, Vol. 52, No. 2, pp. 336-372.

Ben-Shakhar, G., Bornstein, G., Hopfensitz, A. and Van Winden, F. (2007), "Reciprocity and emotions in bargaining using physiological and self-report measures", Journal of Economic Psychology, Vol. 28, No. 3, pp. 314-323.

Bergstrom, T., Blume, L. and Varian, H. (1986), "On the private provision of public goods", Journal of Public Economics, Vol. 29, No. 1, pp. 25-49.

Berscheid, E. and Reiss, H. T. (1998), "Attraction and close relationships", in Gilbert, T., Fiske, S. T. andLindzey, G. (Eds.), The handbook of social psychology, $4^{\text {th }}$ ed., Mc Graw-Hill, New York, pp. 193-281.

Bolton, G. E. and Ockenfels, A. (2000), "ERC: A Theory of Equity, Reciprocity, and Competition", The American Economic Review, Vol. 90, No. 1, pp. 166-193.

Brandts, J., Riedl, A. and Van Winden, F. (2007), "On competition and well-being: an experimental investigation into rivalry, social disposition and subjective well-being", Working paper.

Brunet, E., Sarfati, Y., Hardy-Bayle, M. C. and Decety, J. (2000), "A PET investigation of the attribution of intentions with a nonverbal task", Neuroimage, Vol. 11, No. 2, pp. 15766.

Calder, A. J., Lawrence, A. D. and Young, A. W. (2001), "Neuropsychology of fear and loathing", Nature Reviews Neuroscience, Vol. 2, No. 5, pp. 352-63.

Camerer, C., Loewenstein, G. and Prelec, D. (2005), "Neuroeconomics: How Neuroscience Can Inform Economics", Journal of Economic Literature, Vol. 43, No. 1, pp. 9-64.

Castelli, F., Happe, F., Frith, U. and Frith, C. (2000), "Movement and Mind: A Functional Imaging Study of Perception and Interpretation of Complex Intentional Movement Patterns", NeuroImage, Vol. 12, No. 3, pp. 314-325.

Charness, G. and Rabin, M. (2002), "Understanding social preferences with simple tests", The Quarterly Journal of Economics, Vol. 117, No. 3, pp. 817-89.

Cialdini, R. B., Brown, S. L., Lewis, B. P., Luce, C. and Neuberg, S. L. (1997), "Reinterpreting the Empathy-Altruism Relationship: When One Into One Equals Oneness", Journal of Personality and Social Psychology, Vol. 73, No. 3, pp. 481-494. 
Coleman, J. S. (1990), Foundations of Social Theory, Harvard University Press, Cambridge.

Cox, J. C., Friedman, D. and Gjerstad, S. (2007), "A tractable model of reciprocity and fairness", Games and Economic Behavior, Vol. 59, No. 1, pp. 17-45.

Cox, J. C. and Sadiraj, V. (2007), "On Modeling Voluntary Contributions to Public Goods", Public Finance Review, Vol. 35, No. 2, pp. 311-332.

Damasio, A. R. (2003), Looking for Spinoza: Joy, sorrow and the feeling brain, Harcourt, Orlando, FL.

Damasio, A. R., Grabowski, T. J., Bechara, A., Damasio, H., Ponto, L. L., Parvizi, J. and Hichwa, R. D. (2000), "Subcortical and cortical brain activity during the feeling of selfgenerated emotions", Nature Neuroscience, Vol. 3, No. 10, pp. 1049-56.

Dawes, C. T., Fowler, J. H., Johnson, T., McElreath, R. and Smirnov, O. (2007), "Egalitarian motives in humans", Nature, Vol. 446, No. 7137, pp. 794-6.

De Vignemont, F. and Singer, T. (2006), "The empathic brain: how, when and why?" Trends in Cognitive Sciences, Vol. 10, No. 10, pp. 435-41.

Decety, J. and Chaminade, T. (2003), "Neural correlates of feeling sympathy", Neuropsychologia, Vol. 41, No. 2, pp. 127-38.

Decety, J. and Hodges, S. D. (2006), "The social neuroscience of empathy", in Van Lange, P. A. M. (Ed.), Bridging social psychology: Benefits of transdisciplinary approaches, Erlbaum, Mahwah, pp. 103-109.

Delgado, M. R., Frank, R. H. and Phelps, E. A. (2005), "Perceptions of moral character modulate the neural systems of reward during the trust game", Nature Neuroscience, Vol. 8, No. 11, pp. 1611-8.

Dufwenberg, M. and Kirchsteiger, G. (2004), "A theory of sequential reciprocity", Games and Economic Behavior, Vol. 47, No. 2, pp. 268-298.

Edgeworth, F. Y. (1881), Mathematical Physics, Kegan Paul, London.

Elster, J. (1998), "Emotions and Economic Theory", Journal of Economic Literature, Vol. 36, No. 1, pp. 47-74.

Falk, A. and Fischbacher, U. (2006), "A theory of reciprocity", Games and Economic Behavior, Vol. 54, No. 2, pp. 293-315.

Fehr, E. and Camerer, C. F. (2007), "Social neuroeconomics: the neural circuitry of social preferences", Trends in Cognitive Sciences, Vol. 11, No. 10, pp. 419-27.

Fehr, E. and Schmidt, K. M. (1999), "A Theory of Fairness, Competition, and Cooperation", The Quarterly Journal of Economics, Vol. 114, No. 3, pp. 817-868.

Fehr, E. and Schmidt, K. M. (2005), "The economics of fairness, reciprocity and altruism Experimental evidence and new theories", Working paper.

Fließbach, K., Weber, B., Trautner, P., Dohmen, T., Sunde, U., Elger, C. E. and Falk, A. (2007), "Social comparison affects reward-related brain activity in the human ventral striatum", Science, Vol. 318, No. 5854, pp. 1305-8.

Frijda, N. H. (1986), The emotions, Cambridge University Press, Cambridge.

Fudenberg, D. and Tirole, J. (1991), Game Theory, MIT Press, Cambridge

Gallagher, H. L. and Frith, C. D. (2003), "Functional imaging of 'theory of mind"', Trends in Cognitive Sciences, Vol. 7, No. 2, pp. 77-83.

Gallagher, H. L., Happe, F., Brunswick, N., Fletcher, P. C., Frith, U. and Frith, C. D. (2000), "Reading the mind in cartoons and stories: an fMRI study of 'theory of mind' in verbal and nonverbal tasks", Neuropsychologia, Vol. 38, No. 1, pp. 11-21.

Gallagher, H. L., Jack, A. I., Roepstorff, A. and Frith, C. D. (2002), "Imaging the intentional stance in a competitive game", Neuroimage, Vol. 16, No. 3 Pt 1, pp. 814-21. 
Glimcher, P. W., Dorris, M. C. and Bayer, H. M. (2005), "Physiological utility theory and the neuroeconomics of choice", Games and Economic Behavior, Vol. 52, No. 2, pp. 213256.

Goeree, J. K., Holt, C. A. and Laury, S. K. (2002), "Private costs and public benefits: unraveling the effects of altruism and noisy behavior", Journal of Public Economics, Vol. 83, No. 2, pp. 255-276.

Granovetter, M. (1985), "Economic Action and Social Structure: The Problem of Embeddedness", The American Journal of Sociology, Vol. 91, No. 3, pp. 481-510.

Granovetter, M. S. (1973), "The Strength of Weak Ties", The American Journal of Sociology, Vol. 78, No. 6, pp. 1360-1380.

Güroğlu, B., Haselager, G. J., Van Lieshout, C. F., Takashima, A., Rijpkema, M. and Fernandez, G. (2008), "Why are friends special? Implementing a social interaction simulation task to probe the neural correlates of friendship", Neuroimage, Vol. 39, No. 2, pp. 903-10.

Güth, W., Schmittberger, R. and Schwarze, B. (1982), "An experimental analysis of ultimatum bargaining", Journal of Economic Behavior \& Organization, Vol. 3, No. 4, pp. 367-388.

Harbaugh, W. T., Mayr, U. and Burghart, D. R. (2007), "Neural responses to taxation and voluntary giving reveal motives for charitable donations", Science, Vol. 316, No. 5831, pp. 1622-5.

Haruno, M. and Kawato, M. (2006), "Different neural correlates of reward expectation and reward expectation error in the putamen and caudate nucleus during stimulus-actionreward association learning", Journal of Neurophysiology, Vol. 95, No. 2, pp. 948-59.

Heatherton, T. F., Wyland, C. L., Macrae, C. N., Demos, K. E., Denny, B. T. and Kelley, W. M. (2006), "Medial prefrontal activity differentiates self from close others", Social Cognitive and Affective Neuroscience Vol. 1, No. 1, pp. 18-25.

Homans, G. C. (1950), The Human Group, Harcourt, Brace and World, New York.

Insel, T. R. and Young, L. J. (2001), "The neurobiology of attachment", Nature Reviews Neuroscience, Vol. 2, No. 2, pp. 129-36.

Jenkins, A. C., Macrae, C. N. and Mitchell, J. P. (2008), "Repetition suppression of ventromedial prefrontal activity during judgments of self and others", Proceedings of the National Academy of Sciences U S A, Vol. 105, No. 11, pp. 4507-12.

Keser, C. and Van Winden, F. (2000), "Conditional Cooperation and Voluntary Contributions to Public Goods", Scandinavion Journal of Economics, Vol. 102, No. 1, pp. 23-39.

King-Casas, B., Tomlin, D., Anen, C., Camerer, C. F., Quartz, S. R. and Montague, P. R. (2005), "Getting to know you: reputation and trust in a two-person economic exchange", Science, Vol. 308, No. 5718, pp. 78-83.

Knoch, D., Pascual-Leone, A., Meyer, K., Treyer, V. and Fehr, E. (2006), "Diminishing reciprocal fairness by disrupting the right prefrontal cortex", Science, Vol. 314, No. 5800, pp. 829-32.

Knutson, B. and Bossaerts, P. (2007), "Neural antecedents of financial decisions", Journal of Neuroscience, Vol. 27, No. 31, pp. 8174-7.

Kosfeld, M., Heinrichs, M., Zak, P. J., Fischbacher, U. and Fehr, E. (2005), "Oxytocin increases trust in humans", Nature, Vol. 435, No. 7042, pp. 673-676.

Kreps, D. M., Milgrom, P., Roberts, J. and Wilson, R. (1982), "Rational cooperation in the finitely repeated prisoners' dilemma", Journal of Economic Theory, Vol. 27, No. 2, pp. 245-252. 
Kringelbach, M. L. (2005), "The human orbitofrontal cortex: linking reward to hedonic experience", Nature Reviews Neuroscience, Vol. 6, No. 9, pp. 691-702.

Krueger, F., Mccabe, K., Moll, J., Kriegeskorte, N., Zahn, R., Strenziok, M., Heinecke, A. and Grafman, J. (2007), "Neural correlates of trust", Proceedings of the National Academy of Sciences U S A, Vol. 104, No. 50, pp. 20084-9.

Kuhnen, C. M. and Knutson, B. (2005), "The neural basis of financial risk taking", Neuron, Vol. 47, No. 5, pp. 763-70.

Lamm, C., Batson, C. D. and Decety, J. (2007), "The neural substrate of human empathy: effects of perspective-taking and cognitive appraisal", Journal of Cognitive Neuroscience, Vol. 19, No. 1, pp. 42-58.

Ledyard, J. (1995), Public goods: a survey of experimental research, Princeton University Press, Princeton.

Levine, D. K. (1998), "Modeling Altruism and Spitefulness in Experiments", Review of Economic Dynamics, Vol. 1, No. 3, pp. 593-622.

Liebrand, W. B. G. (1984), "The effect of social motives, communication and group size on behaviour in an N-person multi-stage mixed-motive game", European Journal of Social Psychology, Vol. 14, No. 3, pp. 239-264.

Loewenstein, G. (1996), "Out of Control: Visceral Influences on Behavior", Organizational Behavior and Human Decision Processes, Vol. 65, No. 3, pp. 272-292.

Loewenstein, G. (2000), "Emotions in Economic Theory and Economic Behavior", The American Economic Review, Vol. 90, No. 2, pp. 426-432.

Loewenstein, G. and O'Donoghue, T. (2007), "The heat of the moment: Modeling interactions between affect and deliberation", Working Paper.

Loewenstein, G. and Schkade, D. (1999), "Wouldn't it be nice? Predicting future feelings", in Kahneman, D., Diener, E. and Schwartz, N. (Eds.), Well Being: The Foundations of Hedonic Psychology, Russell Sage Foundation, New York.

Maner, J. K., Luce, C. L., Neuberg, S. L., Cialdini, R. B., Brown, S. and Sagarin, B. J. (2002), "The Effects of Perspective Taking on Motivations for Helping: Still No Evidence for Altruism", Personality and Social Psychology Bulletin, Vol. 28, No. 11, pp. 1601-1610.

McCabe, K., Houser, D., Ryan, L., Smith, V. and Trouard, T. (2001), "A functional imaging study of cooperation in two-person reciprocal exchange", Proceedings of the National Academy of Sciences U S A, Vol. 98, No. 20, pp. 11832-5.

Miller, E. K. and Cohen, J. D. (2001), "An integrative theory of prefrontal cortex function", Annual Review of Neuroscience, Vol. 24, No., pp. 167-202.

Moll, J., Zahn, R., De Oliveira-Souza, R., Krueger, F. and Grafman, J. (2005), "Opinion: the neural basis of human moral cognition", Nature Reviews Neuroscience, Vol. 6, No. 10, pp. 799-809.

Montague, P. R. and Lohrenz, T. (2007), "To detect and correct: norm violations and their enforcement", Neuron, Vol. 56, No. 1, pp. 14-8.

Rabin, M. (1993), "Incorporating Fairness into Game Theory and Economics", The American Economic Review, Vol. 83, No. 5, pp. 1281-1302.

Ridderinkhof, K. R., Ullsperger, M., Crone, E. A. and Nieuwenhuis, S. (2004), "The role of the medial frontal cortex in cognitive control", Science, Vol. 306, No. 5695, pp. 443-7.

Rilling, J., Gutman, D., Zeh, T., Pagnoni, G., Berns, G. and Kilts, C. (2002), "A neural basis for social cooperation", Neuron, Vol. 35, No. 2, pp. 395-405. 
Rilling, J. K., Sanfey, A. G., Aronson, J. A., Nystrom, L. E. and Cohen, J. D. (2004a), "The neural correlates of theory of mind within interpersonal interactions", Neuroimage, Vol. 22, No. 4, pp. 1694-703.

Rilling, J. K., Sanfey, A. G., Aronson, J. A., Nystrom, L. E. and Cohen, J. D. (2004b), "Opposing BOLD responses to reciprocated and unreciprocated altruism in putative reward pathways", Neuroreport, Vol. 15, No. 16, pp. 2539-43.

Rusbult, C. E. and Van Lange, P. A. M. (1996), "Interdependence processes", in Higgins, E. T. and Kruglanski, A. (Eds.), Social psychology: Handbook of basic principles, Guilford, New York, pp. 564-596

Rustichini, A. (2005), "Neuroscience. Emotion and reason in making decisions", Science, Vol. 310, No. 5754, pp. 1624-5.

Sanfey, A. G. (2007), "Social decision-making: insights from game theory and neuroscience", Science, Vol. 318, No. 5850, pp. 598-602.

Sanfey, A. G., Loewenstein, G., Mcclure, S. M. and Cohen, J. D. (2006), "Neuroeconomics: cross-currents in research on decision-making", Trends in Cognitive Sciences, Vol. 10, No. 3, pp. 108-16.

Sanfey, A. G., Rilling, J. K., Aronson, J. A., Nystrom, L. E. and Cohen, J. D. (2003), "The neural basis of economic decision-making in the Ultimatum Game", Science, Vol. 300, No. 5626, pp. 1755-8.

Sawyer, J. (1966), "The Altruism Scale: A Measure of Co-operative, Individualistic, and Competitive Interpersonal Orientation", The American Journal of Sociology, Vol. 71, No. 4, pp. 407-416.

Saxe, R. (2006), "Uniquely human social cognition", Current Opinion in Neurobiology, Vol. 16, No. 2, pp. 235-239.

Schultz, W., Dayan, P. and Montague, P. R. (1997), "A neural substrate of prediction and reward", Science, Vol. 275, No. 5306, pp. 1593-9.

Singer, T., Seymour, B., O'Doherty, J. P., Stephan, K. E., Dolan, R. J. and Frith, C. D. (2006), "Empathic neural responses are modulated by the perceived fairness of others", Nature, Vol. 439, No. 7075, pp. 466-9.

Smith, A. (1759), The theory of moral sentiments, Liberty Fund, Indianapolis.

Sobel, J. (2005), "Interdependent Preferences and Reciprocity", Journal of Economic Literature, Vol. 43, No. 2, pp. 392-436.

Sonnemans, J., Dijk, F. V. and Winden, F. V. (2006), "On the dynamics of social ties structures in groups", Journal of Economic Psychology, Vol. 27, No. 2, pp. 187-204.

Tajfel, H. and Turner, J. C. (1986), "The social identity of inter-group behavior", in Worchel, S. andAustin, L. W. (Eds.), Psychology of intergroup relations, Nelson Hall, Chicago.

Tanaka, S. C., Doya, K., Okada, G., Ueda, K., Okamoto, Y. and Yamawaki, S. (2004), "Prediction of immediate and future rewards differentially recruits cortico-basal ganglia loops", Nature Neuroscience, Vol. 7, No. 8, pp. 887-93.

Taylor, D. M. and Moghaddam, F. M. (1994), Theories of intergroup relations: International social psychological perspectives, Praeger, New York.

Tomlin, D., Kayali, M. A., King-Casas, B., Anen, C., Camerer, C. F., Quartz, S. R. and Montague, P. R. (2006), "Agent-specific responses in the cingulate cortex during economic exchanges", Science, Vol. 312, No. 5776, pp. 1047-50.

Van 'T Wout, M., Kahn, R. S., Sanfey, A. G. and Aleman, A. (2005), "Repetitive transcranial magnetic stimulation over the right dorsolateral prefrontal cortex affects strategic decision-making", Neuroreport, Vol. 16, No. 16, pp. 1849-52. 
Van Dijk, F., Sonnemans, J. and Van Winden, F. (2002), "Social ties in a public good experiment", Journal of Public Economics, Vol. 85, No. 2, pp. 275-299.

Van Dijk, F. and Van Winden, F. (1997), "Dynamics of social ties and local public good provision", Journal of Public Economics, Vol. 64, No. 3, pp. 323-341.

Van Lange, P. A. M., Agnew, C. R., Harinck, F. and Steemers, G. E. M. (1997), "From Game Theory to Real Life: How Social Value Orientation Affects Willingness to Sacrifice in Ongoing Close Relationships", Journal of Personality and Social Psychology, Vol. 73, No. 6, pp. 1330-1344.

Van Winden, F. (2001), "Emotional Hazard Exemplified by Taxation-Induced Anger", Kyklos, Vol. 54, No. 2-3, pp. 491-506.

Zak, P. J., Kurzban, R. and Matzner, W. T. (2005), "Oxytocin is associated with human trustworthiness", Hormones and Behavior, Vol. 48, No. 5, pp. 522-527.

Zak, P. J., Stanton, A. A. and Ahmadi, S. (2007), "Oxytocin Increases Generosity in Humans", PLoS ONE, Vol. 2, No. 11, pp. e1128.

\section{Figures}

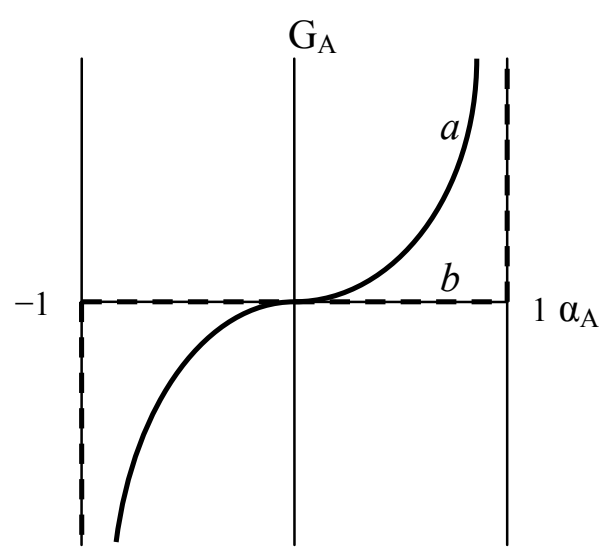

Figure 1. Phase diagram of equation (3): (a) with decay, (b) without decay. 


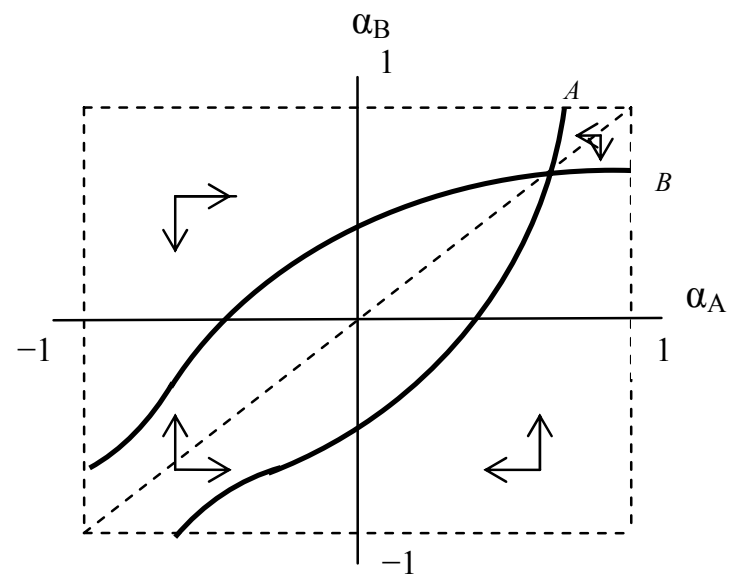

Figure 2. Phase diagram of equations (3) with identical individuals (using $\mathrm{G}_{\mathrm{A}}\left(\alpha_{\mathrm{A}}, \alpha_{\mathrm{B}}\right)$ and $\left.\mathrm{G}_{\mathrm{B}}\left(\alpha_{\mathrm{B}}, \alpha_{\mathrm{A}}\right)\right)$, with $A: f_{A}=0, B: f_{B}=0$.

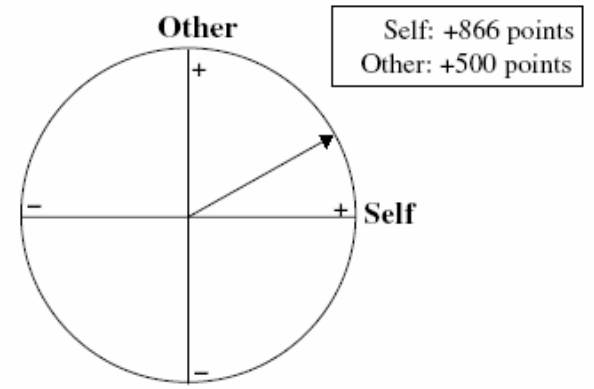

Figure 3. Example of self-other payoff combination in the Ring-test. 